\section{Quetta Earthquake of May 31}

We have received from the Under Secretary of State for India an advance copy of a brief report on the Quetta earthquake. In the loss of human life, it ranks as one of the most destructive of all known Indian earthquakes. Its disturbed area was probably less than 300,000 square miles, while the Assam earthquake of 1897, the Kangra earthquake of 1905 and the North Bihar earthquake of 1934 were all felt over areas of between $1 \frac{1}{2}$ and 2 million square miles. The epicentral area is a band about 70 miles long and 15 miles wide, running from Quetta, through Mastung, to midway between Mastung and Kalat. One of the most striking features of the earthquake was its brief duration, which was probably less than half a minute. The intensity of the shock rapidly diminished from the central area, suggesting that the focus was perhaps not more than a mile or two below the surface. In the district between Peshawar and Karachi, the alignment of the mountain ranges is abruptly broken by a marked re-entrant angle running up through Sibi to Quetta. At the apex of this angle, the rocks must be in a condition of great strain, and it is possibly the sudden yielding of the rocks under this strain that causes the numerous earthquakes in this part of Baluchistan.

\section{Circulation of the Earth's Atmosphere}

AT the International Meteorological Conference at Utrecht in September 1923, a resolution was passed that arose from a proposal of the late Prof. Exner for the calculation of coefficients of correlation between weather anomalies in distant parts of the world. This resolution was to the effect that long and homogeneous series of observations of pressure, temperature and rainfall should be published with the view of furthering the study of the general circulation of the earth's atmosphere ; that a small number of stations at a mutual distance of 500-1,000 kilometres should be included, preferably stations belonging to the Réseau Mondial (a network of stations for which annual summaries are published); and that this material for publication should be collected with the aid of various meteorological institutes, the long series being taken up to the year 1920. This resolution took shape in vol. 79 of the Smithsonian Miscellaneous Collections under the title "World Weather Records", to which has been added recently a supplementary volume with the same title covering the period 1921-30, but also including some summaries of long records that were not available in time for vol. 79. The new material occupies the whole of vol. No. 90 of the same series of Miscellaneous Collections, the cost of publication being met by a grant from Mr. John A. Roebling. It is scarcely necessary to point out the advantage to students of world weather of a collection of data of this kind, which gathers together in a compact form material that is often obtainable only at great trouble and expense. It can be used by those who carry out statistical studies with the view of establishing equations for long-period forecasting on the lines developed by Sir Gilbert Walker and others, and also for the study of periodicities, while the addition of monthly sunspot and solar radiation data makes it possible to add the study of solar-terrestrial rela. tionships. The supplementary material includes the long Edinburgh series, which goes back to 1731 for temperature and to 1770 for precipitation.

\section{Marine Research at Port Erin}

THE main work at the Marine Biological Station, Port Erin, Isle of Man, has been on the rearing of oyster larvæ up to the time that they settle as spat. The report for 1934 (No. 47), drawn up by Dr. R. J. Daniel, shows that many other researches are being carried out, but the grant-in-aid from the Development Commission has made it possible to investigate the feeding of the oyster larvæ. The zooids from certain common seaweeds have been used, and by choosing a succession of different species, zooids of one kind or another are provided throughout the summer months when the oyster larvæ are present in the water. This special research occupies Mr. J. A. Bruce and Dr. Mary Parke. Detailed investigations on the morphology, cytology and life-cycles of the brown seaweeds have been necessary, with the testing of various culture media. The results have so far been of an encouraging nature, and it is hoped to expand the scope of the work in future. Samples of local herring are still continuously examined throughout the fishing season. Lobster culture is also progressing, lobsterlings and younger stages as well as more than $3,000,000$ plaice eggs and larvæ from the pond having been liberated into the sea. The scheme for research also includes work on the conditions and relations of inter-tidal life on the beach. It is satisfactory to see that a large number of visitors, especially classes from schools, have worked at the Laboratory during the year.

\section{Problems of Forestry}

THE fifteenth number of Sylva (published by the Edinburgh University Forestry Society, 1934-35), the annual journal of the Edinburgh University Forestry Society, fully maintains the standard which this publication has achieved. Among the professional articles may be included "Impressions of British Forestry", in which some interesting criticisms are made by H. E. Marées, and a second on "The Forests of Denmark", by N. Bang. Forestry in the Empire is represented by articles on "Forest Research in Trinidad", in which C. Swabey treats of the considerable progress made in this direction in recent years; the "Problem of Forestry in Southern Rhodesia", an article recommended to those interested in that portion of the Empire. Afforestation on the Bauchi Plateau of Northern Nigeria, by J. Dundas, and preliminary notes for a working plan of woodbush forests in South Africa, by C. C. Stapleton, are also discussed. Allusion is also made to the visit paid to West Africa in 1934 by Prof. E. P. Stebbing, during which he saw something of the forests of a number of British and French Colonies, returning home via the Sahara. 